\title{
ANALISIS KUALITAS DAYA PADA PABRIK PT. IDEC ABADI WOOD INDUSTRIES (AWI) TARAKAN
}

\author{
Sonny Riawan \\ Jurusan Teknik Elektro Universitas Borneo Tarakan, Kota Tarakan, Kaltara, Indonesia \\ email: sonny.riawan@gmail.com
}

\begin{abstract}
In an industry or factory needs a good power quality, because the factory is widely used electronic devices that are directly related to the production process. It is therefore necessary to study related to the quality of electric power in order to find out good or bad quality of electric power in an industry or factory. The study was conducted at PT. IDEC AWI Tarakan. PT IDEC has a Steam Power Plant with a capacity of $7 \mathrm{MW}$, some energi used for the factory and the remainder distributed to the PT. PLN Tarakan. The used data in this study form a line diagram of PT. IDEC AWI Tarakan, load data, channel data and the peak load data factory in the evening. The study was conducted by taking the case under normal conditions, without the capacitor condition and repair condition. To simulate and analyze power system, used in this study ETAP PowerStation 5.0.3 software with the power flow studies using Newton-Raphson method.
\end{abstract}

Keywords-Power factor, capacitors, power loss.

Intisari-Dalam sebuah industri atau pabrik dibutuhkan kualitas daya yang baik, karena pada pabrik banyak digunakan peralatan-peralatan elektronika yang berhubungan langsung dengan proses produksi. Oleh karena itu perlu dilakukan penelitian yang berhubungan dengan kualitas daya listrik dengan tujuan agar dapat mengetahui baik atau buruk kualitas daya listrik pada suatu industri atau pabrik. Penelitian dilakukan di PT. IDEC AWI Tarakan. PT IDEC memiliki Pembangkit Listrik Tenaga Uap (PLTU) dengan kapasitas 7 MW. Daya yang dibangkitkan sebagian digunakan untuk keperluan pabrik dan selebihnya disalurkan ke PT. PLN Tarakan. Data yang digunakan dalam penelitian ini berupa diagram segaris PT. IDEC AWI Tarakan, data beban, data saluran dan data beban puncak pabrik pada malam hari. Penelitian dilakukan dengan mengambil kasus pada kondisi normal, kondisi tanpa kapasitor dan kondisi perbaikan. Untuk mensimulasikan dan menganalisa sistem tenaga listrik, dalam penelitian ini digunakan software ETAP PowerStation 5.0.3 dengan studi aliran daya menggunakan metode Newton-Raphson.

Kata kunci-Faktor daya, kapasitor, rugi-rugi daya.

\section{PENDAHULUAN}

Besaran listrik yang diperhatikan dan sekaligus menentukan baik atau buruk kualitas daya listrik di pabrik yaitu tegangan, arus, frekuensi, faktor daya, dan pentanahan. Perhatian terhadap kualitas daya saat ini semakin meningkat seiring dengan peningkatan penggunaan energi listrik dan peralatan kelistrikan, kualitas daya listrik adalah setiap masalah daya listrik yang berbentuk penyimpangan tegangan, arus, atau frekuensi yang mengakibatkan kegagalan ataupun kesalahan operasi pada peralatan-peralatan yang terjadi pada konsumen energi listrik.

Daya adalah suatu nilai energi listrik yang dibangkitkan dan didistribusikan ke beban, besarnya daya listrik tersebut sebanding dengan perkalian besarnya tegangan dan arus listriknya.Energi listrik yang dipakai oleh PT. IDEC AWI Tarakan dibangkitkan oleh Pembangkit Listrik Tenaga Uap (PLTU) milik PT. IDEC AWI Tarakan dengan kapasitas $7 \mathrm{MW}$, sebesar $3 \mathrm{MW}$ untuk pemakaian sendiri dan selebihnya disalurkan ke PT. PLN Tarakan. Pada proses produksi di pabrik PT. IDEC AWI. Oleh karena itu maka perlu dilakukan penelitian yang membahas tentang: parameter kelistrikan yaitu tegangan, faktor daya, daya aktif, daya reaktif dan daya kompleks, daya listrik, perbaikan kualitas daya, juga Untuk memperoleh informasi tentang baik atau buruknya kualitas daya di pabrik PT. IDEC AWI Tarakan, solusi perbaikan kualitas daya pada pabrik PT. IDEC AWI Tarakan.

\section{METODE PENELITIAN}

Sifat-sifat sistem distribusi yang baik yaitu: Kontinuitas, Luasan dan Penyebaran, Fleksibel, Kualitas daya. Berikut ini merupakan detail penjelasan komponen tersebut.

\section{A. Tegangan Listrik}

Potensial V sebagai kerja (sumber dari Beda luar) yang digunakan untuk memindahkan suatu muatan listrik positif dari suatu titik ke titik yang lain adalah perubahan energi potensial listrik yang sebanding dengan muatan listriknya :

$V=\frac{w}{q}=-\int_{\text {awal }}^{a k h i r} E \cdot d \ell$

Toleransi tegangan boleh naik atau turun yang diijinkan berdasarkan Standar PLN adalah $+5 \%$ dan $-10 \%$.

\section{B. Arus Listrik}

Arus listrik diukur dalam satuan Ampere (A), adalah satu Coulomb per detik. Arus listrik di rumuskan

$I=\frac{d q}{d t}$

C. Daya dan Faktor Daya

Daya adalah suatu ukuran terhadap penggunaan energi dalam suatu waktu tertentu. 
$p=\frac{E}{t}$

Daya nyata atau daya aktif adalah daya listrik yang digunakan secara nyata, misalnya untuk menghasilkan panas, cahaya, energi kinetik yaitu pada motor listrik. Daya reaktif dihasilkan oleh beban-beban yang bersifat reaktansi, terdapat dua jenis beban reaktansi yaitu reaktansi induktif dan reaktansi kapasitif. Daya kompleks atau lebih sering dikenal sebagai daya semu adalah penjumlahan secara vektor antara daya aktif dan daya reaktif.

$S=P+j Q$

Daya kompleks dinyatakan dengan satuan VA (Volt Ampere) adalah hasil kali antara besarnya tegangan dan arus listrik yang mengalir pada beban.

$S=V \cdot I$

Hubungan ketiga buah daya listrik yaitu daya aktif $\mathrm{P}$, daya reaktif $\mathrm{Q}$, serta daya kompleks $\mathrm{S}$, dinyatakan dengan sebuah segitiga yang disebut dengan segitiga daya

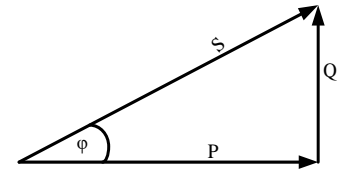

Gambar 1. Segitiga daya

antara ketiga daya listrik dapat dinyatakan persamaan daya kompleks :

$S=\sqrt{P^{2}+Q^{2}}$

Persaaman daya aktif :

$P=S \cos \varphi$

$P=V I \cos \varphi$

Persamaan daya reaktif :

$\mathrm{Q}=\mathrm{S} \sin \varphi$

$Q=V I \sin \varphi$

Faktor daya :

$\cos \varphi=p f=\frac{P}{S}$

\section{Monitoring kualitas daya}

Monitoring atau pemantauan kualitas daya adalah proses pengumpulan dan pengambilan data, menganalisis, dan menginterpretsikan data pengukuran tersebut menjadi suatu informasi yang bermanfaat. Program monitoring kualitas daya dilakukan karena adanya permintaan untuk meningkatkan kualitas sistem daya menjadi lebih baik. Beberapa tujuan dari monitoring kualitas daya adalah Monitoring untuk mengetahui kinerja system, Monitoring untuk menjelaskan masalah-masalah tertentu, Monitoring untuk memprediksi waktu pemeliharaan peralatan
E. Identifikasi Permasalahan Kualitas Daya

Beberapa informasi yang digunakan untuk mengidentifikasi per-masalahan dalam kualitas daya listrik. Permasalahan alami, seperti kegagalan peralatan, kesalahan fungsi dari sistem kendali dan peralatan, Kapan terjadinya suatu kegagalan dalam sistem tenaga listrik, Terjadinya permasalahan atau kegagalan operasi dalam suatu waktu yang sama, Sumber-sumber yang dapat menyebabkan variabel pada kualitas daya, sepetri starting motor, switching kapasitor, penggunaan peralatan elektronika daya, peralatan yang menghasilkan busur api, Kondisi peralatan tenaga listrik yang terpasang, Data sistem tenaga listrik, seperti diagram segaris/single line, ukuran dan impedansi transformator, dan informasi beban listrik.

\section{F. Studi Aliran Daya}

Persamaan umum untuk arus yang mengalir menuju suatu bus:

$I_{1}=Y_{11} V_{1}+Y_{12} V_{2}+Y_{13} V_{3}+\cdots+Y_{1 n} V_{n}$

$I_{2}=Y_{21} V_{1}+Y_{22} V_{2}+Y_{23} V_{3}+\cdots+Y_{2 n} V_{n}$

$I_{3}=Y_{31} V_{1}+Y_{32} V_{2}+Y_{33} V_{3}+\cdots+Y_{3 n} V_{n} I_{n}=Y_{n 1} V_{1}+$

$Y_{n 2} V_{2}+Y_{n 3} V_{3}+\cdots+Y_{n n} V_{n}$

Dapat juga ditulis dengan persamaan:

$I_{P}=\sum_{q=1}^{n} Y_{p q} V_{q} ; p=1,2,3, \cdots, n$

G. Metode Newton-Raphson

Pada metode Newton-Raphson, slack bus diabaikan dari perhitungan iterasi untuk menentukan tegangantegangan, karena besar dari sudut tegangan pada slack bus telah ditentukan. Sedangkan pada generator bus, daya aktif dan magnitude tegangan bernilai tetap, sehingga hanya daya reaktif yang dihitung pada setiap iterasinya

\section{HASIL DAN PEMBAHASAN}

Data parameter kelistrikan, beban dan saluran

A. Data Parameter Kelistrikan

Tabel I

Data Parameter Kelistrikan PT. IDEC AWI Tarakan

\begin{tabular}{|c|c|c|c|c|c|c|}
\hline \multirow{2}{*}{$\begin{array}{c}\text { P } \\
\text { (MW) }\end{array}$} & \multirow{2}{*}{$\begin{array}{c}\text { Q } \\
\text { (MVar) }\end{array}$} & \multirow{2}{*}{ S } & \multicolumn{3}{|c|}{ Tegangan (V) } & \multirow{2}{*}{ Cos } \\
\cline { 4 - 6 } & & & Input & L-L & L-N & $\boldsymbol{\varphi}$ \\
\hline 2.600 & 1.107 & 2.826 & 20000 & 400 & 230 & 0.92 \\
\hline
\end{tabular}

Tegangan yang dipakai di pabrik untuk produksi seharihari $400 \mathrm{~V}$ tegangan antar fasa $\left(\mathrm{V}_{\mathrm{LL}}\right)$ dan $230 \mathrm{~V}$ tegangan fasa ke netral $\left(\mathrm{V}_{\mathrm{LN}}\right)$

\section{B. Data Saluran Penghantar}

Data saluran penghantar yang diperlukan untuk penelitian ini adalah data panjang saluran penghantar, jenis saluran penghantar, diameter penghantar, jumlah penghantar per fasa serta nilai tahanan (R) dan reaktansi (X) untuk tiap-tiap penghantar. 
Tabel II

Nilai Resistansi dan Reaktansi Kabel

\begin{tabular}{|c|c|c|c|}
\hline Penghantar & $\begin{array}{c}\text { Ukuran } \\
\left(\mathbf{m m}^{\mathbf{2}}\right)\end{array}$ & $\begin{array}{c}\mathbf{R} \\
(\mathbf{O h m} / \mathbf{k m})\end{array}$ & $\begin{array}{c}\mathbf{X} \\
(\mathbf{O h m} / \mathbf{k m})\end{array}$ \\
\hline \multirow{4}{*}{ Tembaga } & 50 & 0.379 & 0.189 \\
\cline { 2 - 4 } & 70 & 0.262 & 0.210 \\
\cline { 2 - 4 } & 95 & 0.189 & 0.203 \\
\cline { 2 - 4 } & 120 & 0.150 & 0.196 \\
\cline { 2 - 4 } & 150 & 0.122 & 0.192 \\
\cline { 2 - 4 } & 185 & 0.0972 & 0.184 \\
\cline { 2 - 4 } & 240 & 0.0740 & 0.174 \\
\hline
\end{tabular}

Untuk menentukan Nilai R dan X kabel

$\mathrm{R}=0.379 \mathrm{Ohm} / \mathrm{km}$

$\mathrm{X}=0.189 \mathrm{Ohm} / \mathrm{km}$

Panjang kabel $=100 \mathrm{~m}$

Sehingga:

$$
\begin{aligned}
& R=\frac{0.379}{1000} \times 100 \\
& R=0.0379 \Omega
\end{aligned}
$$$$
X=\frac{0.189}{1000} \times 100
$$$$
\mathrm{X}=0.0189 \Omega
$$

\section{Sistem Tenaga Listrik PT. IDEC AWI Tarakan}

Generator PT. IDEC AWI Tarakan merupakan Turbin Generator sinkron 3 Fasa, arus bolak-balik yang bekerja pada frekuensi $50 \mathrm{~Hz}$. Tegangan yang dibangkitkan oleh generator, bernilai $6.3 \mathrm{kV}$ dengan daya sebesar $7 \mathrm{MW}$ yang kemudian dihubungkan ke sisi primer trafo daya dengan hubungan delta-bintang $(\Delta-\mathrm{Y})$ dan keluaran pada sisi sekundernya $20 \mathrm{kV}$, yang selanjutnya tegangan $20 \mathrm{kV}$ diturunkan melalui Transformator 1 dan Transformator 2 menjadi $400 \mathrm{~V}$ untuk tegangan antar fasa $\left(\mathrm{V}_{\mathrm{LL}}\right)$ atau 230 $\mathrm{V}$ untuk tegangan fasa ke netral $\left(\mathrm{V}_{\mathrm{LN}}\right)$.

\section{Tabel III}

Daftar jurusan Trafo 1 dan 2 PT. IDEC AWI Tarakan

\begin{tabular}{|c|c|l|}
\hline Trafo & $\begin{array}{c}\text { Feeder } \\
\text { (Penyulang) }\end{array}$ & \multicolumn{1}{c|}{ Bagian } \\
\hline 1 & Feeder 1 & Genset Room, MDP I Pabrik \\
\hline 2 & Feeder 2 & $\begin{array}{l}\text { MDP II Pabrik, MDP III Saw } \\
\text { Mill, MDP IV Boiler 50 T }\end{array}$ \\
\hline
\end{tabular}

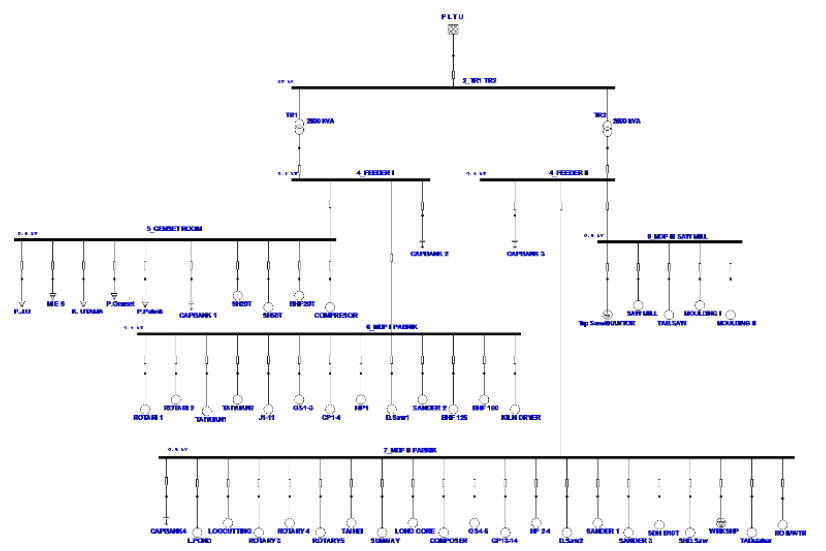

Gambar 2. Diagam Segaris PT. IDEC AWI Tarakan
D. Studi Aliran Daya

Membuat plant, Penomoran dan penamaan busbar, Input data. Beberapa contoh data yang harus di input pada software ETAP PowerStation 5.0.3 dengan paramater sebagai berikut:

1. Data power grid

Berikut ini adalah data power grid.

$\mathrm{V}=20 \mathrm{kV}$.

$\mathrm{P} \quad=7 \mathrm{MW}$

grounding $=\mathrm{Y}$ (bintang)

Mode $\quad=$ Swing

2. Data transformator

Berikut ini adalah data TR1 dan TR2.

$\mathrm{VA} \quad=2500 \mathrm{kVA}$.

Rating $=20 / 0.4 \mathrm{kV}$

Belitan $\Delta$-Y Solid (delta-bintang).

3. Data busbar

Tegangan pada Bus disesuaikan dengan koneksi/hubungan yang dilakukan dengan detail data sebagai erikut
$\mathrm{P} \quad=200 \mathrm{~kW}$.
$\mathrm{V} \quad=0.4 \mathrm{kV}$
$\mathrm{PF} \quad=80 \%$
$\mathrm{EFF} \quad=90 \%$

Pembebanan $80 \%$ pada Design, 4 Pole.

4. Beban statis

$\mathrm{VA}=35 \mathrm{kVA}$

$\mathrm{V} \quad=0.4 \mathrm{kV}$.

$\mathrm{PF} \quad=80 \%$.

Pembebanan $80 \%$ pada design.

5. Beban lumped

$\mathrm{VA}=56 \mathrm{kVA}$.

$\mathrm{V} \quad=0.4 \mathrm{kV}$

$\mathrm{PF} \quad=80 \%$

Amps $=85$.

dengan perbandingan beban motor $80 \%$ dan beban statis $20 \%$ pada pembebanan $80 \%$ yang mempunyai ketentuan:

a. Daya yang dipakai pabrik dalam kondisi normal yaitu sesuai dengan beban puncak yang telah ditentukan.

b. Tegangan di tiap-tiap bus berada dalam batas-batas yang diijinkan yaitu $+5 \%-10 \%$.

c. Daya yang mengalir pada penghantar berada dalam batas kapasitas penghantar.

d. Daya kompleks (VA) pada transformator berada dalam batas kapasitas transformator yang diberikan.

e. Kapasitor beroperasi secara normal sesuai dengan kondisi lapangan. 
Perbandingan total pembangkitan

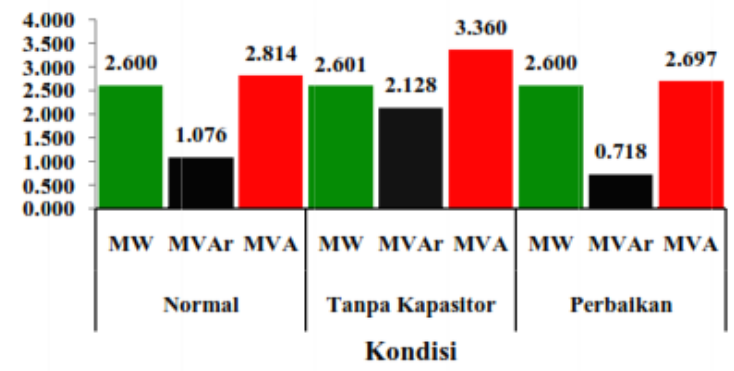

Gambar 3 Grafik perbandingan total pembangkitan

Perbandingan rugi-rugi daya

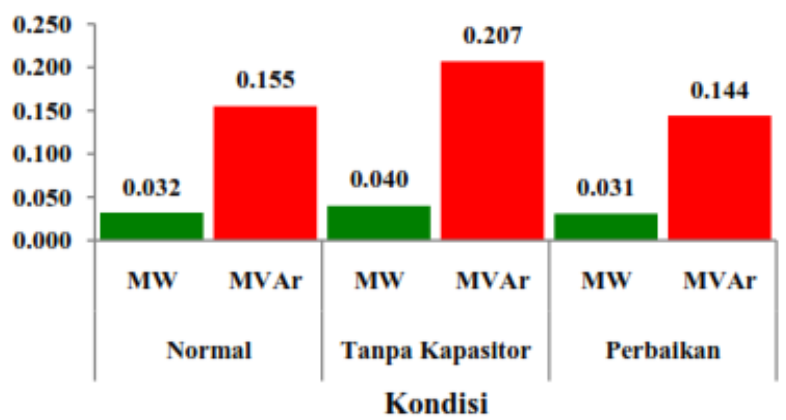

Gambar 4 Grafik perbandingan total rugi-rugi daya

Berdasarkan hasil studi aliran daya, Gambar 4.10 grafik perbandingan total rugi-rugi daya, menampilkan informasi besarnya rugi-rugi daya pada ketiga kondisi, berdasarkan Gambar 4.10 dapat diketahui besarnya rugirugi daya pada kondisi normal sebesar 0.032 MW dan 0.155 MVAr, pada kondisi perbaikan rugirugi daya sebesar 0.031 MW dan 0.144 MVAr lebih kecil dari kondisi normal, sedangkan pada kondisi tanpa kapasitor rugi-rugi daya sebesar 0.040 MW dan 0.207 MVAr lebih besar dari kondisi normal.

\section{IV.KESIMPULAN}

Pada kondisi beban puncak normal yaitu kondisi beban puncak malam pukul 20.00 WITA dengan kapasitor beroperasi normal faktor daya pada bus pembangkit sebesar 92.4\%. Pada kondisi beban puncak tanpa menggunakan kapasitor, faktor daya pada bus pembangkit sampai penyulang tidak mencapai $80 \%$ sehingga terjadi undervoltage pada beberapa bagian pabrik yaitu pada Sander_1 dan Sander_3. Pada kondisi analisa percobaan yaitu pembagian kapasitor bank yang ada di Feeder/penyulang I dibagi dua untuk dipasang di MDP I, faktor daya pada bus penyulang I dan II naik sampai $90 \%$. Berdasarkan hasil simulasi sistem tenaga listrik degan software ETAP PowerStation 5.0.3, Kualitas daya pada pabrik PT. IDEC AWI Tarakan masuk dalam golongan kualitas daya yang baik, dilihat dari power faktor yang mencapai $90 \%$ dan kemungkinan kecil terjadinya undervoltage pada ujung terima/beban. Pengoperasian Bank Kapasitor pada industri cukup penting selain untuk mempebaiki factor daya juga sebagai penurun losses/ rugi-rugi daya.

\section{UCAPAN TERIMA KASIH}

Terima kasih penulis ucapkan kepada segenap pihak yang secara langsung maupun tidak langsung telah berkontribusi baik terhadap proses penyusunan tulisan ini maupun dalam proses publikasinya. Terima kasih kepada para autor yang naskahnya penulis jadikan sebagai referensi.

\section{REFERENSI}

[1] Kurniawan Dzackiy, U. Simulasi Aliran Daya Pada Penyulang Dua Gardu Induk Rawalo Dengan Menggunakan Software ETAP 7.0. 2011

[2] LPPM-ITS, Modul Pelatihan ETAP Level-1, Modul Pelatihan, Fakultas Teknologi Industri, Institut Teknologi Sepuluh November, Surabaya. 2008

[3] Noviariant, Analisa Kualitas Daya dan Harmonisa, 2011

[4] Roger C. Dugan, Mc Granaghan. F. M, Santoso. S, Beaty Wayne. H, Electrical Power Systems Quality, 2nd edition, Downloaded from Digital Engineering Library @ McGrawHill. 2011 